\title{
Glycosylation changes triggered by the differentiation of monocytic THP-1 cell line into macrophages
}

Clément P. Delannoy, Yoann Rombout ${ }^{\dagger}$, Sophie Groux-Degroote, Stephanie Holst, Bernadette Coddeville, Anne Harduin-Lepers, Manfred Wuhrer, Elisabeth Elass-Rochard, Yann Guérardel

Fig. S1: MS/MS sequencing of permethylated Gb4/GA1 extracted from PMAdifferentiated cells at $\mathbf{m} / \mathbf{z} 1460$ and 1572. Analysis of the two GB4/GA1 isomers established that the 112 mass unit difference is due to the ceramide moieties at $\mathrm{m} / z 548$ (Cer*) or $m / z 660\left(\mathrm{Cer}^{* *}\right)$.

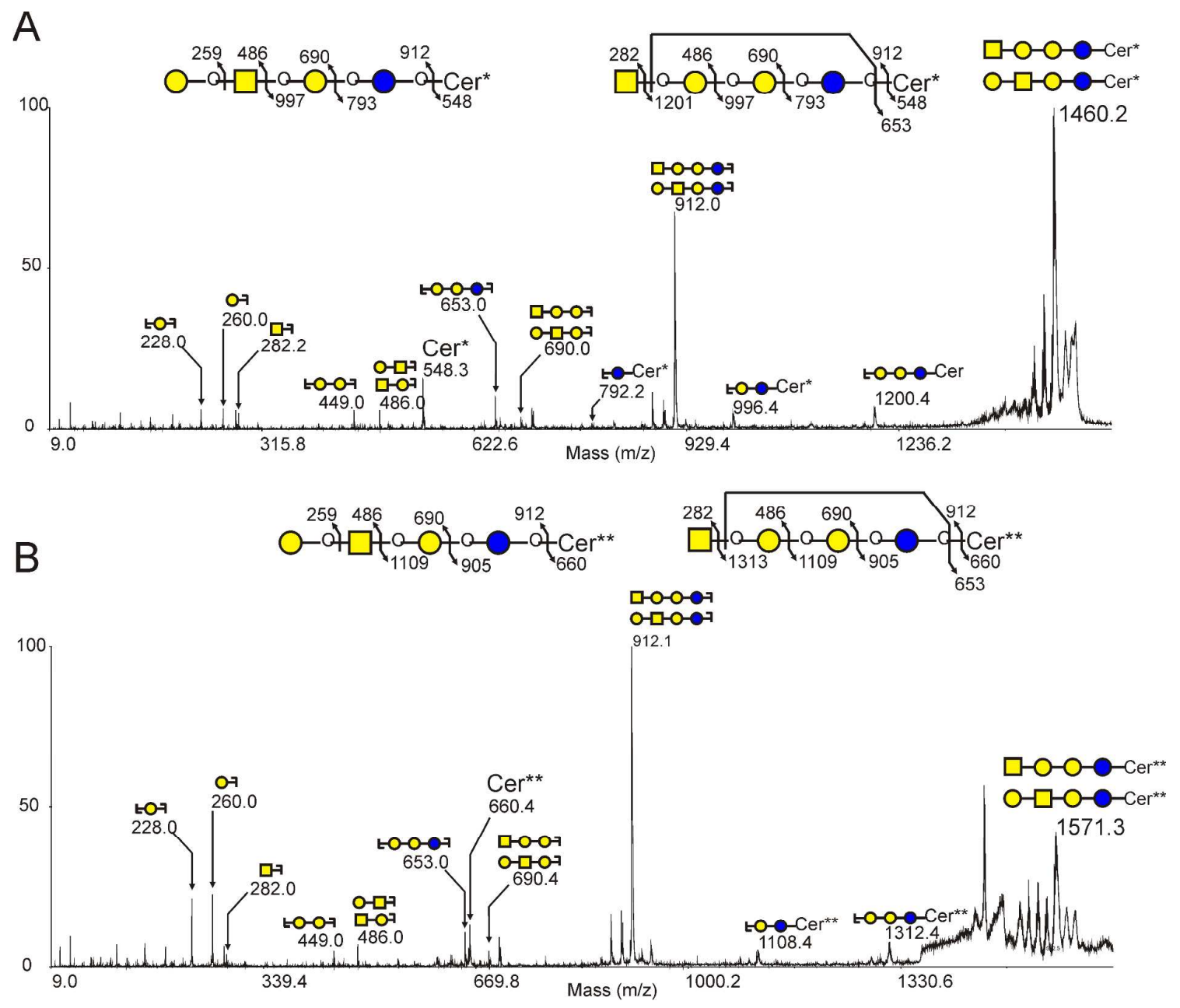


Fig. S2: MS/MS sequencing of permethylated GD1a extracted from PMA-differentiated THP-1 cells at $\mathbf{m} / \mathbf{z}$ 2294.3. Fragment ions were annotated according to nomenclature of Domon and Costello [25]. The nature of monosaccharides was deduced from known biosynthesis pathway of gangliosides.

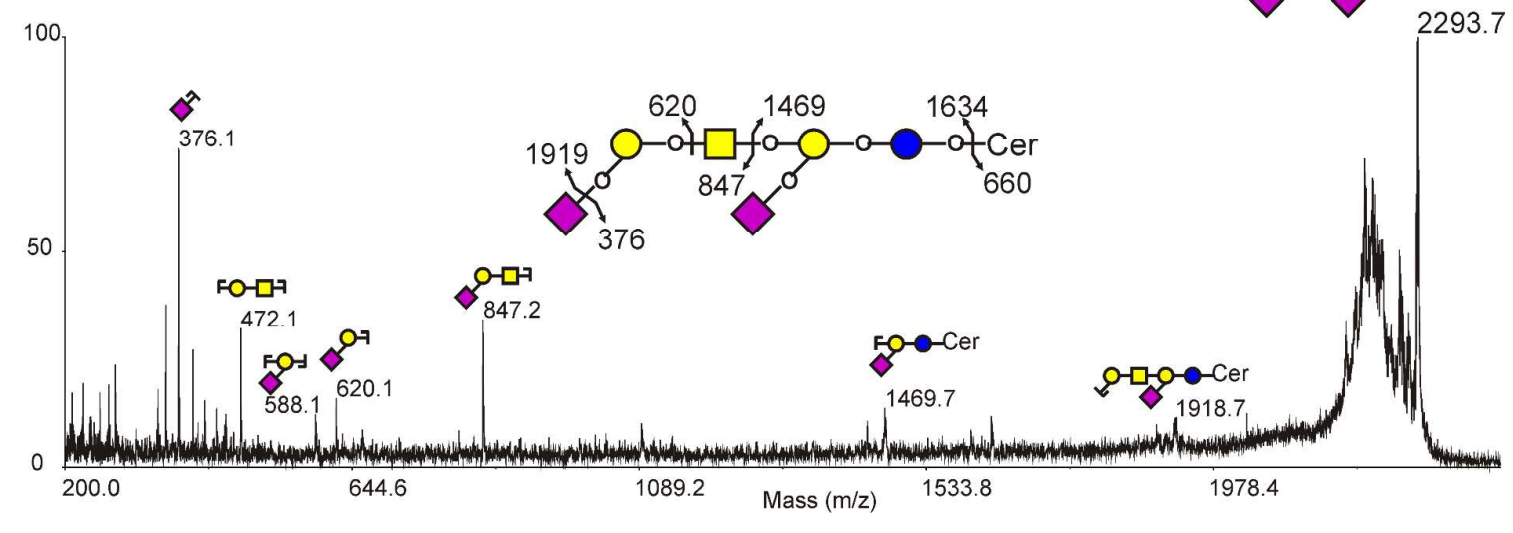


Fig. S3: MS/MS sequencing of complex type N-glycans from undifferentiated (A) and PMA-differentiated THP-1 cells (B) at $m / z$ 2967.5. Fragment ions were annotated according to nomenclature of Domon and Costello [25].

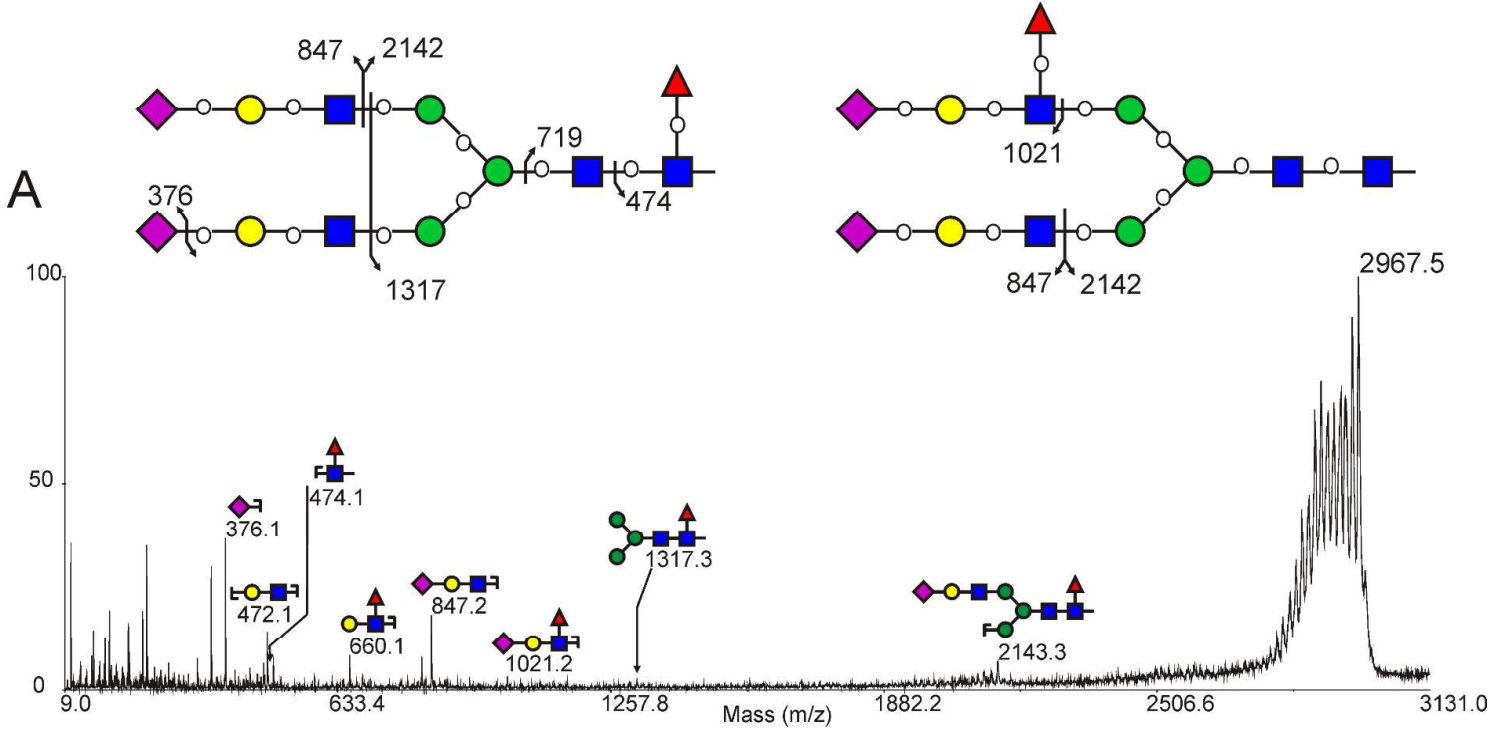

B

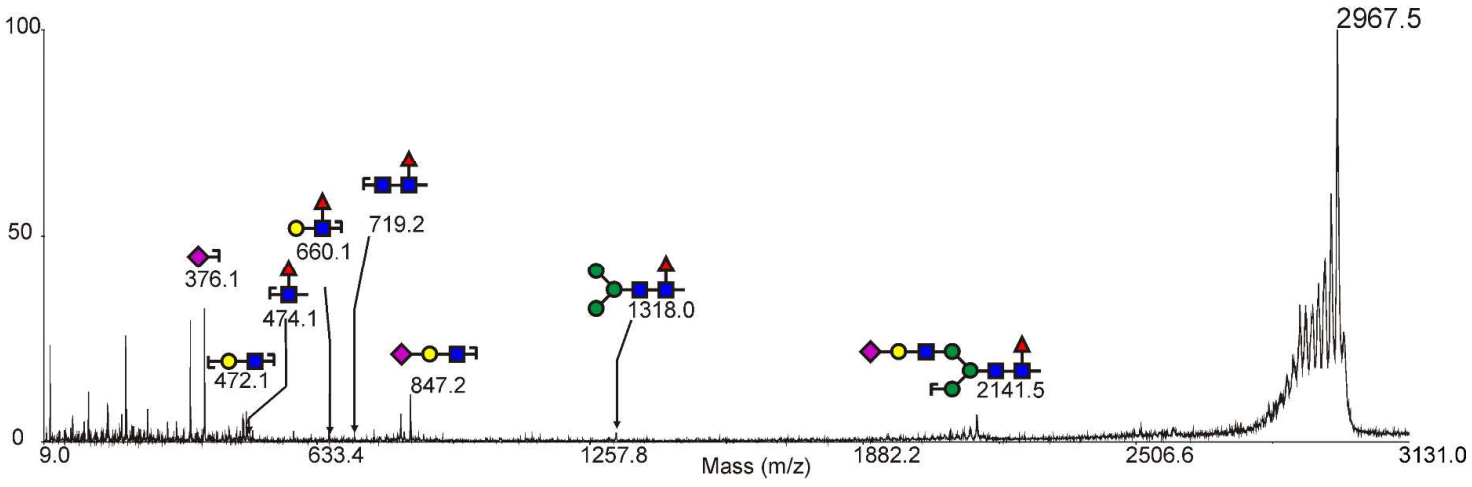


Fig. S4: Structural modification of N-glycans profile upon THP-1 differentiation by MS analysis of ethyl-esterified glycans. (A) Ratios of complex and high-mannose types NGlycans on THP-1 cells; (B) Fucosylation of complex type N-glycans; (C) Proportions of multi-antennary complex-type N-glycans. White bars: Undifferentiated THP-1; gray bars: PMA-differentiated THP-1. Statistical significance compared with undifferentiated cells $(* * * \mathrm{p}<0.001 ; * * \mathrm{p}<0.01)$ was determined by a two-tailed t-test using GraphPad Prism 5 software. Data represent median \pm interquartile range from six different experiments.

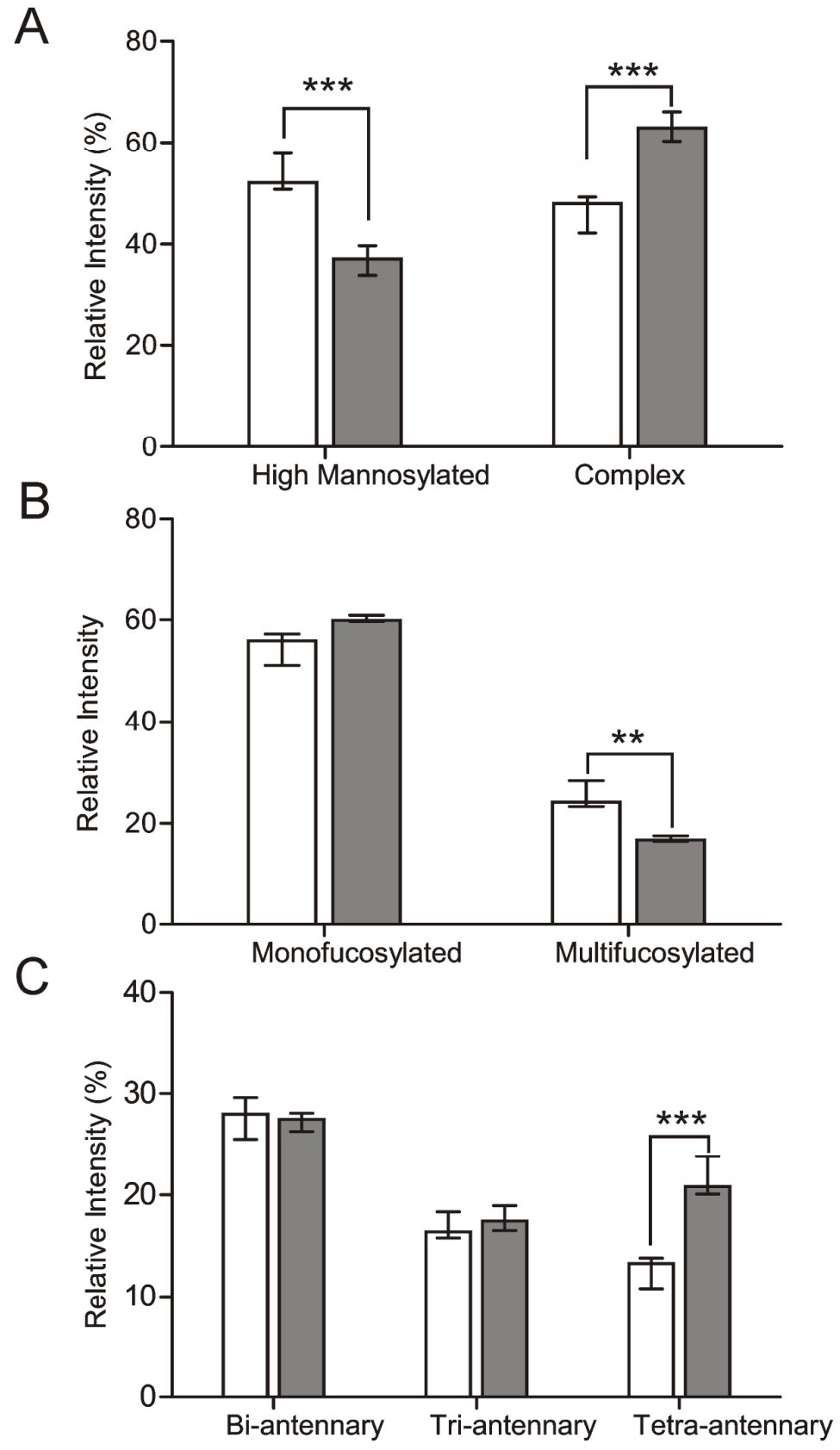


Fig. S5: Quantification of high molecular N-glycans by MS analysis of ethyl-esterified glycans. Average relative amounts of the most abundant polyLacNAc N-glycans of undifferentiated THP-1 cells (white bars) and PMA-differentiated THP-1 cells (gray bars). Statistical significance compared with undifferentiated cells $(* * * p<0.001 ; * * p<0.01)$ is determined by a t-test using GraphPad Prism 5 software. Data represent median \pm interquartile range from three different experiments.

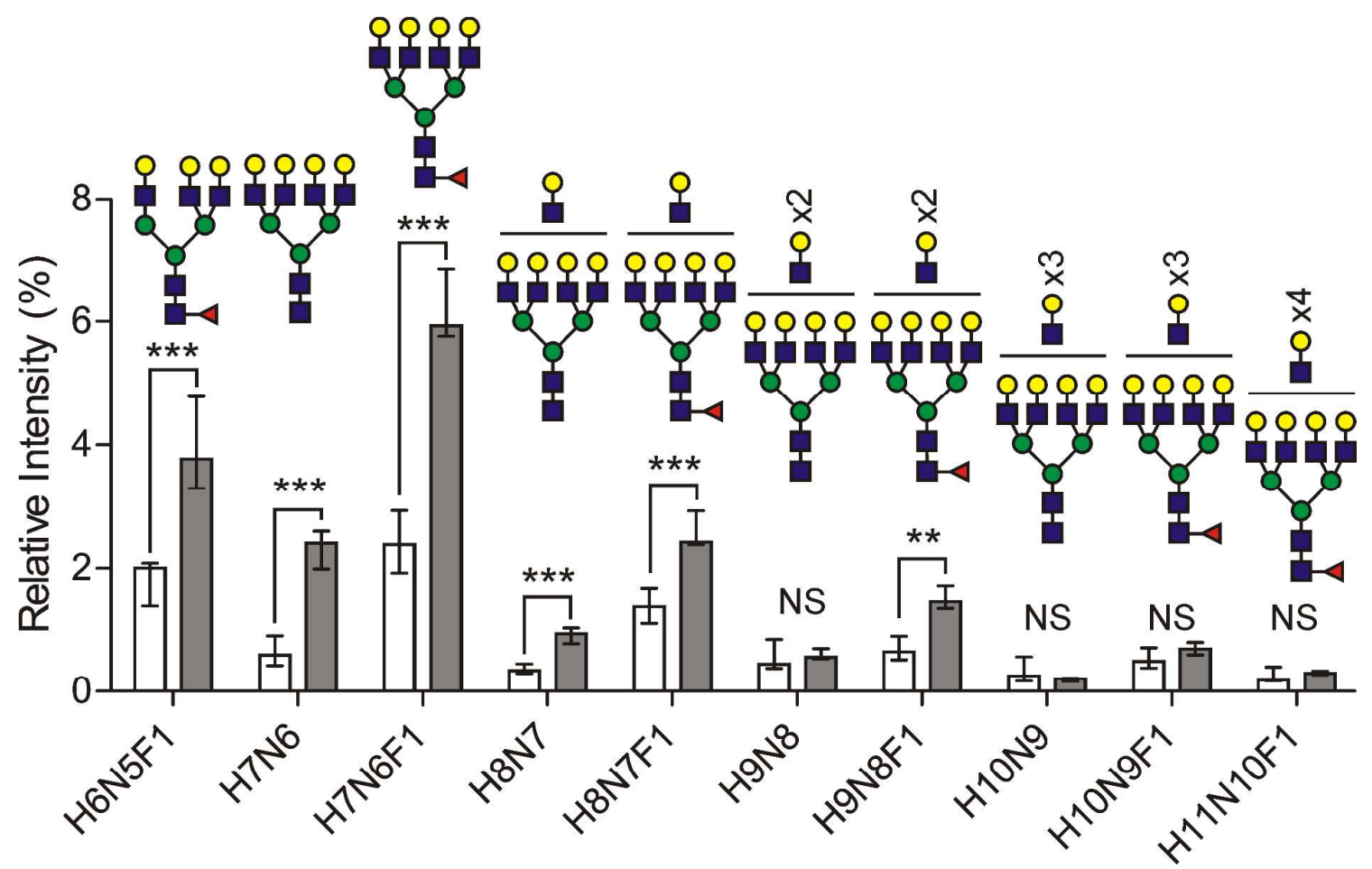


Fig. S6: Sialylation of complex type N-glycans by MS analysis of ethyl-esterified glycans. White bars: Undifferentiated THP-1 cells; gray bars: PMA-differentiated THP-1 cells. Statistical significance compared with undifferentiated cells $\left({ }^{*} \mathrm{p}<0.05\right)$ is determined by a two-tailed t-test using GraphPad Prism 5 software. Data represent median \pm interquartile range from three different experiments.

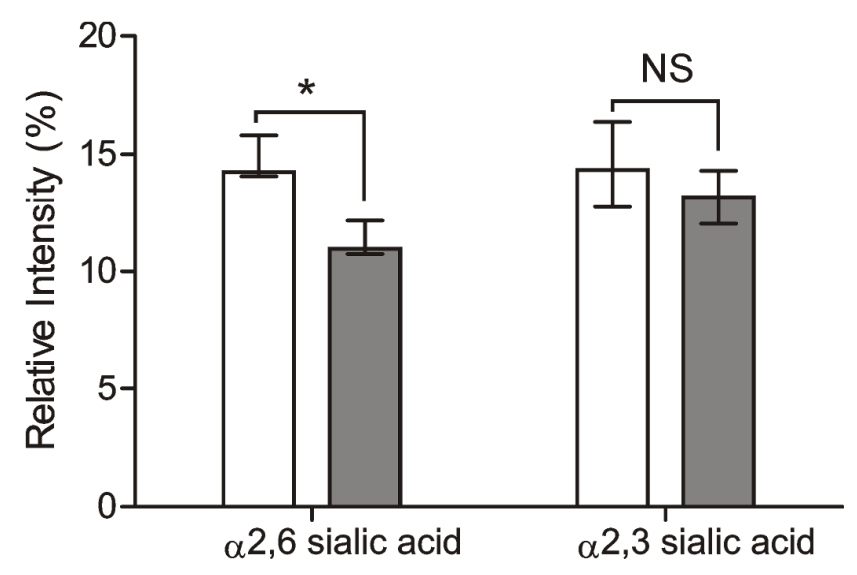

